\title{
Twenty Years of Schizophrenia Research in the Northern Finland Birth Cohort 1966: A Systematic Review
}

\author{
Erika Jääskeläinen, ${ }^{1,2,3}$ Marianne Haapea, ${ }^{2,3,4}$ Nina Rautio, ${ }^{1,2,5}$ Pauliina Juola, ${ }^{2,3,4}$ \\ Matti Penttilä, ${ }^{2,3,4}$ Tanja Nordström, ${ }^{1,2}$ Ina Rissanen, ${ }^{1,2,3}$ Anja Husa, ${ }^{2,3,4}$ Emmi Keskinen, ${ }^{1,2,3}$ \\ Riikka Marttila, ${ }^{1,2,3}$ Svetlana Filatova, ${ }^{1,2,3,4}$ Tiina-Mari Paaso, ${ }^{1,2}$ Jenni Koivukangas, ${ }^{3,6}$ \\ Kristiina Moilanen, ${ }^{2,3,4}$ Matti Isohanni, ${ }^{3,4}$ and Jouko Miettunen ${ }^{1,2,3,4}$ \\ ${ }^{1}$ Center for Life Course Epidemiology and Systems Medicine, University of Oulu, P.O. Box 5000, 90014 Oulu, Finland \\ ${ }^{2}$ Medical Research Center Oulu, Oulu University Hospital and University of Oulu, P.O. Box 5000, 90014 Oulu, Finland \\ ${ }^{3}$ Department of Psychiatry, Center for Clinical Neurosciences, University of Oulu, P.O. Box 5000, 90014 Oulu, Finland \\ ${ }^{4}$ Department of Psychiatry, Oulu University Hospital, P.O. Box 26, 90029 Oulu, Finland \\ ${ }^{5}$ Unit of Primary Health Care, Oulu University Hospital, P.O. Box 10, 90029 Oulu, Finland \\ ${ }^{6}$ Aurora Doctoral Programme, Thule Institute, University of Oulu, P.O. Box 7300, Oulu, Finland
}

Correspondence should be addressed to Erika Jääskeläinen; erika.jaaskelainen@oulu.fi

Received 11 January 2015; Revised 24 April 2015; Accepted 29 April 2015

Academic Editor: Hugo Schnack

Copyright (C) 2015 Erika Jääskeläinen et al. This is an open access article distributed under the Creative Commons Attribution License, which permits unrestricted use, distribution, and reproduction in any medium, provided the original work is properly cited.

Birth cohort designs are useful in studying adult disease trajectories and outcomes, such as schizophrenia. We review the schizophrenia research performed in the Northern Finland Birth Cohort 1966 (NFBC 1966), which includes 10,934 individuals living in Finland at 16 years of age who have been monitored since each mother's mid-pregnancy. By the age of 44, 150 (1.4\%) had developed schizophrenia. There are 77 original papers on schizophrenia published from the NFBC 1966. The early studies have found various risk factors for schizophrenia, especially related to pregnancy and perinatal phase. Psychiatric and somatic outcomes were heterogeneous, but relatively poor. Mortality in schizophrenia is high, especially due to suicides. Several early predictors of outcomes have also been found. Individuals with schizophrenia have alterations in brain morphometry and neurocognition, and our latest studies have found that the use of high lifetime doses of antipsychotics associated with these changes. The schizophrenia research in the NFBC 1966 has been especially active for 20 years, the prospective study design and long follow-up enabling several clinically and epidemiologically important findings. When compared to other birth cohorts, the research in the NFBC 1966 has offered also unique findings on course and outcome of schizophrenia.

\section{Introduction}

Birth cohort studies were originally designed to study early health outcomes, but as the earliest birth cohorts started in the 1940s to the 1960s have matured, adult outcomes have also been studied [1]. Welham and colleagues [1] reviewed birth cohort studies on antecedents of schizophrenia, finding 11 birth cohorts from seven countries. The authors concluded that birth cohort studies have provided important insights into how the premorbid developmental trajectory of individuals who develop schizophrenia differs from their peers.
The Northern Finland Birth Cohort 1966 (NFBC 1966) is a birth cohort which has been studied extensively with almost 1000 peer-review publications in various fields of medicine (http://www.oulu.fi/nfbc). The NFBC 1966 was collected during the mid-1960s by paediatrician and Professor of Public Health Paula Rantakallio, the first aim being to analyze perinatal health [2]. In the 1980s, adolescent health and, in the 1990s, adult somatic and psychiatric disorders emerged as the main foci. Schizophrenia research in the NFBC 1966 has been especially active, with the first studies performed in the mid-1990s. The first studies focused on early risk factors, but 
later on clinical and social outcomes, neurocognition, brain morphometry, somatic illnesses, and genetics have also been studied.

In this paper, we systematically review the schizophrenia research performed in the NFBC 1966.

\section{Methods}

2.1. Literature Search. The literature search was completed in PubMed in September 2014. The keywords included "Northern Finland Birth Cohort" and words related to schizophrenia (including schizotypy and psychotic disorders). Additionally, we manually searched for articles from the extensive publication list maintained by the NFBC 1966 (http://www.oulu.fi/nfbc). We found 77 original articles related to schizophrenia. In addition, previous reviews from the NFBC 1966 were utilized in this review.

2.2. Sample. The sample was drawn from the NFBC 1966, which is based on 12,068 pregnant women and their 12,058 live-born babies in two northernmost Finnish provinces (Oulu and Lapland), with an expected date of birth during 1966 [2]. The live-births in this study represent $96 \%$ of all births in the region. The information has been collected during pregnancy, delivery, childhood, and the follow-up periods at adulthood. The schizophrenia studies are based on 10,934 cohort members who lived in Finland in 1982. The original articles of this literature review are largely based on three data collections: the 31-year follow-up of the cohort members alive in 1997, and two smaller psychiatric follow-up studies. Register data and earlier collected data of the NFBC 1966 have also been utilized in the studies. The overall study design has been approved and is under the review of the Ethical Committee of the Northern Ostrobothnia Hospital District.

The 31-year follow-up of the whole cohort was conducted in 1997. Comprehensive data on somatic and mental health and the use of health services and medications as well as socioeconomic status were collected using a postal questionnaire $(N=8,297)$. A clinical examination of the cohort members living in Northern Finland or Helsinki area included, for instance, a blood sample draw, which has been utilized in genetic studies $(N=5,960)$. Additional questionnaires including, for example, schizotypal traits, were also filled in $(N=5,084)[41]$.

The 34-year follow-up for psychoses was conducted in 1999-2001. Cohort members with a psychotic episode by the end of the year 1997 (cases) were detected using the Finnish Hospital Discharge Register (FHDR), currently known as Care Register for Health Care. The control subjects were selected randomly from the cohort members without a psychotic episode, living in the region of Oulu. The 34-year follow-up consisted of structural magnetic resonance imaging (MRI) of the brain (GE Signa 1.5T scanner), measures of cognitive functioning, psychiatric interviews, and questions related to, for example, the use of antipsychotic medication, social background, and substance use. In the 34-year followup, 91 cases with a psychotic disorder (61 with schizophrenia) and 104 controls participated and provided written informed consent $[42,43]$.

The 43-year follow-up for psychoses was conducted in 2008-2010. In addition to those with regard to whom a psychosis had been detected during the 34-year follow-up, those who had developed a psychosis between the years 1998 and 2008 according to the nationwide registers or selfreport were invited to participate. The new control subjects were selected randomly from all the cohort members. The procedure was extended from the 34-year follow-up with functional MRI and more measures of cognitive functioning. Out of the eligible subjects, 107 cases with a psychotic disorder (54 with schizophrenia) and 194 controls participated and provided written informed consent. Of the participants, 54 cases with a psychotic disorder (40 with schizophrenia) and 76 controls participated, both at ages 34 and 43 [44].

2.3. Diagnostics. The diagnoses of the participants of the 34 year follow-up were validated in accordance with DSM-III-R $[45,46]$. New cases with schizophrenia and other psychoses have been included in the later studies: these cases are detected continuously from several nationwide registers. Due to the more comprehensive set of registers, the later studies include more outpatients than the previous studies.

\section{Risk Factors}

The first schizophrenia studies in the NFBC 1966 focused on risk factors. The main results of the studies are presented in Table 1. Twenty original studies and also some reviews (e.g., [47]) concerning the various risk factors of schizophrenia have been published. These risk factors can be divided into risks during pregnancy and birth, childhood, and adolescence and later premorbid factors.

The most essential risk factors identified in the latest NFBC 1966 review [47] were male gender, parental psychosis, unwanted pregnancy, perinatal brain damage, low birth weight, late age at learning to stand and walk, not being pottytrained by the age of one, central nervous system infections by the age of 14 years, and not attending normal school grade.

Later, other risk factors have also been found, such as severe injuries [19] and both high and low birth length and weight $[5,10]$. New aspects of the studies were to link parental psychosis and known risk factors $[5,22,24]$ and to study their interactions. It has been found, for instance, that the presence of early biological risk factors increased the risk of schizophrenia only among those with parental psychosis [5] and that low birth weight and length increased the risk only among those without parental psychosis, whereas high birth weight and length did so only among those with parental psychosis [5].

In each stage of human development, there are risk factors influencing the occurrence of schizophrenia. It is important to identify the risk and create awareness among health professionals and decision makers to develop and implement preventive strategies, though it should be noted that most of the effect sizes detected are small or medium level. In schizophrenia risk studies in general, the risk factors with highest quality evidence have shown medium effect sizes [48]. 
TABLE 1: Risk factors of schizophrenia in the Northern Finland Birth Cohort 1966.

\begin{tabular}{|c|c|}
\hline Risk factors & Risk estimates \\
\hline \multicolumn{2}{|r|}{ Pregnancy and birth } \\
\hline Male gender & Risk of schizophrenia OR 1.8 (95\% CI 1.1-3.0) $[3,4]$ \\
\hline Parental psychosis & Risk of schizophrenia HR 2.8 (95\% CI 1.7-4.5) [5] \\
\hline $\begin{array}{l}\text { Maternal antenatal } \\
\text { depression }\end{array}$ & Nonsignificant risk of schizophrenia RR 1.5 (95\% CI 0.9-2.4) [6] \\
\hline $\begin{array}{l}\text { Unwantedness of a } \\
\text { pregnancy }\end{array}$ & Risk of schizophrenia OR 2.4 (95\% CI 1.2-4.8) [7] \\
\hline $\begin{array}{l}\text { High paternal social class at } \\
\text { birth (females) }\end{array}$ & Risk of schizophrenia RR 2.4 (95\% CI 1.2-4.9) [8] \\
\hline Perinatal brain damage & Risk of schizophrenia OR 4.6 (95\% CI 1.7-12.1) $[3,9]$ \\
\hline $\begin{array}{l}\text { Deviant intrauterine } \\
\text { growth }\end{array}$ & $\begin{array}{l}\text { Increased risk of schizophrenia for both low (OR 2.5; 95\% CI 1.2-5.1) and high (OR 2.4; 95\% CI 1.1-4.9) } \\
\text { birth weight and for both low (OR 2.6; 95\% CI 1.1-5.9) and high (OR 1.8; 95\% CI 1.0-3.5) birth length } \\
{[5,9,10]}\end{array}$ \\
\hline Birth order & $\begin{array}{l}\text { Risk of schizophrenia among male first-borns (observed-expected ratio } 1.5 ; 95 \% \text { CI 1.0-2.2) and } \\
\text { nonsignificant risk among female last-borns }(1.3 ; 95 \% \text { CI } 0.9-1.9) \text { [11] }\end{array}$ \\
\hline $\begin{array}{l}\text { Grand multiparity, six or } \\
\text { more }\end{array}$ & $\begin{array}{l}\text { Nonsignificant risk of schizophrenia OR } 1.1 \text { (95\% CI 0.6-2.1), significant risk of other psychosis OR } 2.3 \\
(95 \% \text { CI 1.2-4.7) [12] }\end{array}$ \\
\hline \multicolumn{2}{|r|}{ Childhood and adolescence } \\
\hline $\begin{array}{l}\text { Use of vitamin D } \\
\text { supplementation, at least } \\
2000 \mathrm{IU}\end{array}$ & Decreased risk of schizophrenia RR range: $0.08-0.23$ [13] \\
\hline $\begin{array}{l}\text { Markers of development in } \\
\text { childhood }\end{array}$ & $\begin{array}{l}\text { Risk of schizophrenia, later age of learning to stand (RR 1.5; 95\% CI 1.0-2.2) and walk (RR 1.3; 95\% CI } \\
1.0-1.6)[14]\end{array}$ \\
\hline $\begin{array}{l}\text { Family type (single-parent } \\
\text { versus two-parent) at birth } \\
\text { to } 14 \text { years }\end{array}$ & No significant differences [15] \\
\hline $\begin{array}{l}\text { Viral central nervous } \\
\text { system infection before age } \\
14\end{array}$ & Risk of schizophrenia OR 4.8 (95\% CI 1.6-14.0) $[3,16]$ \\
\hline $\begin{array}{l}\text { Intelligence Quotient (IQ) } \\
<85 \text { up to the age of } 14 \text { years }\end{array}$ & Risk of schizophrenia OR 4.8 (95\% CI 2.2-10.3) [3] \\
\hline $\begin{array}{l}\text { Excellent school } \\
\text { performance age } 16 \text { years } \\
\text { (males) }\end{array}$ & Risk of schizophrenia OR 3.8 (95\% CI 1.6-9.3) [17] \\
\hline $\begin{array}{l}\text { Lower school marks and } \\
\text { below normal class age } 16 \\
\text { years }\end{array}$ & $\begin{array}{l}\text { Lower school marks associated with risk for nonpsychotic disorders, but not for schizophrenia or other } \\
\text { psychoses. Below normal class associated with schizophrenia risk in boys OR } 2.8 \text { (95\% CI 1.5-5.7) [18]. }\end{array}$ \\
\hline \multicolumn{2}{|r|}{ Other premorbid factors } \\
\hline $\begin{array}{l}\text { Severe injuries (e.g., } \\
\text { fractures) before onset of } \\
\text { psychosis }\end{array}$ & Risk of psychotic disorder, having a fracture HR 2.9 (95\% CI 1.4-6.0) [19] \\
\hline Seasonality & Rate of first admission for schizophrenia lower in spring compared to other seasons [20] \\
\hline Paternal age & No significant risk by paternal age categories [21] \\
\hline \multicolumn{2}{|r|}{ Interaction studies } \\
\hline $\begin{array}{l}\text { Parental psychosis and } \\
\text { maternal antenatal } \\
\text { depression }\end{array}$ & $\begin{array}{l}\text { Risk of schizophrenia highest in the offspring with both maternal depressed mood during pregnancy } \\
\text { and parental psychosis (OR 9.4; 95\% CI 4.2-20.9) [22] }\end{array}$ \\
\hline $\begin{array}{l}\text { Parental psychosis and } \\
\text { early risk factors }\end{array}$ & $\begin{array}{l}\text { Risk for schizophrenia highest among those with parental psychosis and biological risk factor: parental } \\
\text { psychosis and high birth weight HR } 7.9 \text { ( } 95 \% \text { CI 1.8-34.8), parental psychosis and high birth length HR } \\
4.3(95 \% \text { CI 1.1-16.2), parental psychosis and any biological risk HR } 3.6 \text { (95\% CI 1.3-10.3), and parental } \\
\text { psychosis and high maternal education HR 0.2 (95\% CI 0.1-0.9) [5] }\end{array}$ \\
\hline
\end{tabular}


TABLE 1: Continued.

\begin{tabular}{|c|c|}
\hline Risk factors & Risk estimates \\
\hline \multicolumn{2}{|r|}{ Associations between risk factors } \\
\hline $\begin{array}{l}\text { Motor performance at age } 1 \\
\text { and school performance at } \\
\text { age } 16\end{array}$ & $\begin{array}{l}\text { Age of learning to stand associated with school mark of physical education in schizophrenia but not in } \\
\text { controls [23] }\end{array}$ \\
\hline $\begin{array}{l}\text { Parental psychosis and } \\
\text { advanced paternal age }\end{array}$ & Maternal schizophrenia associated with higher advanced paternal age [24] \\
\hline
\end{tabular}

$\mathrm{OR}=$ odds ratio, $\mathrm{CI}=$ confidence interval, $\mathrm{HR}=$ hazard ratio, $\mathrm{RR}=$ risk ratio, and $\mathrm{IU}=$ international unit.

TABLE 2: Predictors of poor outcomes in schizophrenia in the Northern Finland Birth Cohort 1966.

\begin{tabular}{ll}
\hline Definition of poor outcome & Predictor of poor outcome \\
\hline & \multicolumn{1}{c}{ Poor clinical outcomes } \\
& Family history of psychosis \\
& Sociodemographic factors: father's high social class \\
(i) More hospitalizations, & Childhood development: earlier age of learning to stand or walk \\
rehospitalization after first episode & Illness-related factors: insidious mode of illness onset, suicidal ideations at first episode, short first \\
[25-30] & hospitalization, long DUP in short-term, and short DUP in long-term \\
& Brain morphology: reduced density of the left limbic area \\
& Adolescence factors: smoking at age 14 years, poorer school performance at high school \\
& Illness-related factors: earlier age at onset, poor work adjustment at illness onset, single at illness \\
(ii) More symptoms, lack of & onset, psychosocial stressor before illness onset, and more symptoms at first episode \\
remission [27, 29, 31, 32] & Temperament traits: lower reward dependence and persistence \\
& Brain morphology: decreased white matter volume \\
(iii) Treatment resistance [33] & Higher birth length and weight \\
\hline & Childhood and adolescence factors: lack of friends at childhood, poorer school performance at \\
(i) Poor occupational functioning & high school \\
(ii) Disability pension & Illness-related factors: earlier age of illness onset, single at illness onset \\
(iii) Low score on SOFAS & Temperament traits: lower persistence and higher harm avoidance \\
[25, 29, 32, 34, 35] & Brain morphology: reduced density of the grey matter in left frontal lobe and left limbic area
\end{tabular}

DUP $=$ duration of untreated psychosis, SOFAS = Social and Occupational Functioning Assessment Scale.

\section{Course of Illness and Outcomes}

4.1. Course of Illness and Outcomes. In the NFBC 1966 on average of ten years from the onset of illness, the outcomes were heterogeneous, but relatively poor [25, 49]. A total of $81 \%$ of subjects with schizophrenic psychoses needed rehospitalization [26]. Adult educational level was significantly lower in subjects with schizophrenia, compared to the controls [50].

At the age of 34, outcomes were heterogeneous and varied largely, depending on the measures of outcomes. More than half $(56 \%)$ of the individuals with schizophrenia were on disability pension [34], whereas $21 \%$ were in symptomatic remission, with only $3.4 \%$ having recovered $[25,49]$. These numbers are somewhat smaller than the average rate of recovery (13.5\%) worldwide, based on a meta-analysis [51].

4.2. Predictors of Outcomes. There are several relevant predictors of outcomes, but especially factors related to illness onset are significant to course of illness. Statistically significant predictors of poor outcomes are presented in Table 2. Many of these factors are not modifiable, but some could possibly be affected by means of early interventions, for example, duration of untreated psychosis (DUP) [52]. One of the most important factors associated with poor outcome in schizophrenia is the early age of illness onset [27], and in the future it is necessary to further study ways to delay the onset of psychosis [53].

Clinical and functional course of illness associates also with biological markers: earlier motor development at age one [28] and morphological abnormalities in several brain areas at age 34 [29] associated with poor outcomes. The difference in early development and brain morphology in good and poor outcomes may reflect separable aetiologies and developmental trajectories in schizophrenia.

\section{Brain Morphometry}

5.1. Differences between Individuals with Schizophrenia and Controls. Differences between subjects with schizophrenia and controls in brain volumes and densities in several brain regions were found at the 34-year follow-up. Subjects with schizophrenia showed 2-3\% lower whole brain, grey matter (GM), and white matter (WM) volumes and 7\% higher 
cerebrospinal fluid volume when compared to controls [54]. Subjects with schizophrenia showed reduced density of GM in several brain regions, for example, frontal, temporal, parietal, and occipital regions at the 34-year follow-up. WM deficits in inter- and intrahemispheric tracts were also found in these lobes. Increased GM density was found, for example, in basal ganglia [55].

The volume of hippocampus was reduced in individuals with schizophrenia or any psychosis when compared to the controls, but the difference was explained by the total brain volume reduction. In the amygdala, significant volume differences between individuals with schizophrenia and controls were not found [56].

5.2. Predictors of Brain Morphometry. At age 34, associations between GM and WM densities and earlier onset age (i.e., longer duration of illness) were found [55]. One study also detected that longer DUP associated with lower GM density of the right limbic area [57]. Earlier infant motor development associated with greater density of GM in, for example, premotor cortex and WM in frontal and parietal lobes in control group, but these associations were not significant in schizophrenia [58].

Between 34 and 43 years of age, Veijola et al. [37] found the rate of annual brain volume reduction to be greater in the schizophrenia group $(0.69 \%)$ than in the controls $(0.49 \%)$. The greatest volume loss in schizophrenia occurred in the temporal lobe and periventricular area. The high amount of antipsychotic medication predicted excessive brain volume loss.

\section{Cognition}

Neurocognitive performance, longitudinal change in cognition, and their associations with infant motor developmental markers, brain volume change, and antipsychotic medication have all been studied in the NFBC 1966 in schizophrenia in comparison with nonpsychotic controls.

6.1. Developmental Markers and Cognition. Delayed infant motor development was associated with poorer adult cognition in schizophrenia at the age of 34 years in executive functions, verbal learning, and visuospatial working memory, but not in visual learning [59]. Earlier motor development, better adult executive functions, and higher grey matter density in frontocerebellar systems were associated with each other in controls, but there was a disruption of these normative associations in schizophrenia at 34 years [58].

Age of learning to stand in infancy significantly inversely predicted later deterioration of executive functions with memory in adult schizophrenia between 34 and 43 years of age [60]. This connection between delayed infant development and greater cognitive decline in adulthood may possibly suggest a link between abnormal neurodevelopmental and neurodegenerative processes in schizophrenia [60].

6.2. Longitudinal Change of Cognitive Performance. Global cognitive functioning as well as performance in domains of executive functions, working memory, and visual and verbal memory were lower in subjects with schizophrenia in comparison to control subjects cross-sectionally, both at the age of $34[37,38,58-60]$ and $43[37,38,60]$. No significantly greater decrease in overall cognition [37] or in verbal learning [61], visual learning, or executive functions without memory component [60] was observed during midlife in schizophrenia, compared to the controls. All in all, change of cognition in schizophrenia followed mostly normative agerelated decline [61]. The only exception for this pattern was the significant deterioration of executive functions with the memory component in cases compared to controls [60]. The results of mostly no deterioration extend the findings of other studies that have shown no decline in cognition around illness onset and first episode [62] also to later stages of illness in schizophrenia.

6.3. Antipsychotic Medication and Cognition. Higher lifetime antipsychotic medication exposure was associated with poorer verbal learning and memory performance at the age of 34 and greater decline in verbal learning and memory between the ages of 34 and 43 years [38]. Although antipsychotic exposure also predicted brain volume reduction in schizophrenia during that time, this volume reduction was not associated with a decrease in overall cognition or specific cognitive processes [37], so the associations between antipsychotic medication, cognition, and longitudinal brain changes seem complex in schizophrenia.

\section{Somatic Illnesses, Mortality, and Criminality}

7.1. Smoking and Somatic Illnesses. In the NFBC 1966, the proportion of smokers was about 50\% among people with schizophrenia and the initiation of regular smoking was closely associated with the onset of the disorder [63]. Riala et al. [64] found poor premorbid school performance to associate with later cigarette smoking among schizophrenia patients. People with psychotic disorders have increased weight gain [65] and individuals with schizophrenia had almost a 4 -fold risk of metabolic syndrome by the age of 31 [66]. The prevalence of metabolic syndrome among individuals with schizophrenia varied between 19 and 29\%, depending on the measurement criteria [66, 67], and $45 \%$ had insulin resistance [68]. Total cholesterol and triglyceride levels were higher in schizophrenia compared to the controls [69], especially among those who used antipsychotic medication [40]. Also, higher triglyceride levels have been found among people with early-onset (less than 20 years of age) of schizophrenia [70]. These results imply that regular monitoring and active treatment of metabolic abnormalities are important already at a relatively young age in schizophrenia.

In addition, in the NFBC 1966, schizophrenia has been associated strongly with epilepsy by the age of 28 years, neurological diseases in general, and inflammatory bowel diseases [71], but rheumatoid arthritis and appendicitis were not more common than in the general population [72].

7.2. Mortality and Suicidality. In the NFBC 1966, the overall mortality rate among subjects with schizophrenia was $14 \%$ 
TABLE 3: Factors associated with the use of antipsychotic medication in the Northern Finland Birth Cohort 1966.

\begin{tabular}{ll}
\hline Factors & Effect of higher use of antipsychotic medication \\
\hline Sex & Females used more often medication [36] \\
Age at onset of psychosis & No association [36] \\
Psychiatric hospital treatment & Increased need of hospital treatment [36] \\
Clinical measures (PANSS, CGI, SOFAS, and remission)Poorer clinical and social outcome [36] \\
Occupational functioning & Higher rate of disability pensions and lower rate of employment [36] \\
Brain volume loss & Increased brain loss [37] \\
Change of cognition & Decline of verbal learning and memory [38] \\
Suicidal ideation & No association when symptoms of depression and anxiety were controlled for [39] \\
Hyperlipidemia & Increased risk of hyperlipidemia [40] \\
\hline
\end{tabular}

PANSS = Positive and Negative Syndrome Scale, CGI = Clinical Global Impression, and SOFAS = Social and Occupational Functioning Assessment Scale

before the age of 27 years, with half of the deaths being suicides [73]. The suicide rate among people with schizophrenia before the age of 39 was $7 \%$ with $71 \%$ of suicides occurring during the first three years after the onset of illness [74]. Good school performance at the age of 16 years increased the risk of suicide in schizophrenia and other psychoses but decreased risk of suicide in the healthy controls [75]. A history of attempted and committed suicides associated with specific genetic traits among schizophrenic males [76], and the use of antipsychotic medication increased the risk of suicidal ideation among people with schizophrenia, but this association disappeared when adjusted for the severity of depression and anxiety symptoms [39].

7.3. Criminality and Violent Behavior. Those with psychotic disorders exhibited higher risks of criminal behavior [77], and increased risk for violent behavior was associated with schizophrenia and coexisting alcohol abuse [78] or with alcohol-induced psychoses [77]. Men with schizophrenia with comorbid alcohol abuse were also more likely to repeat the violent crimes [78]. However, also men with schizophrenia without alcohol abuse were more likely to commit violent crimes, but none of the women with schizophrenia had committed any crimes in the NFBC 1966 by the age of 26 [78].

\section{Antipsychotic Medication}

8.1. Use of Antipsychotic Medication. In the NFBC 1966, the associations between the use of antipsychotic medication and related factors have been extensively studied [36-40]. The predictors and consequences of the use of antipsychotic medication in schizophrenia are described in detail in Table 3. Of the predictors studied, only female gender was found to be a significant predictor of the use of antipsychotic medication.

8.2. Antipsychotic Medication and Outcome. The use of antipsychotic medication predicted an overall poorer outcome; for example, subjects using antipsychotics needed more hospital treatment, had poorer clinical and social outcomes, and were more often unemployed or on disability pension [36]. The subjects using antipsychotic medication had increased risk of hyperlipidemia compared to subjects not using antipsychotics [40]. Use of antipsychotic medication associated with increased suicidal ideation and symptoms of depression and anxiety [39].

8.3. Antipsychotic Medication, Brain Morphometry, and Cognition. Higher cumulative antipsychotic medication exposure (chlorpromazine equivalent dose-years) over the 9-year follow-up between the two brain scans was associated with brain volume reduction [37] and higher cumulative lifetime antipsychotic medication exposure associated with poorer performance and decline in verbal learning and memory in midlife in schizophrenia [38]. These associations remained statistically significant even after controlling for illness severity. Schizophrenia subjects with high antipsychotic doses declined more than the controls in some verbal learning and memory measures, whereas cognitive change in subjects with low doses did not differ from the controls [38]. The annual reduction in brain volume was significantly predicted by exposure to atypical antipsychotics but not typical antipsychotics [37], but higher exposure to both typical and atypical antipsychotics by the age of 34 associated with poorer verbal learning and memory [38].

\section{Schizotypal Traits and Genetic Research}

9.1. Schizotypal Traits as a Marker of Schizophrenia Risk. Schizophrenia is a highly heritable disease. Recently, the Schizophrenia Working Group of the Psychiatric Genomics Consortium [79] identified 128 independent associations spanning 108 conservatively defined loci that met genomewide significance. The consortium also included data from the NFBC 1966. The genetic studies utilizing only the NFBC 1966 data have focused on schizotypal traits as an indication of schizophrenia risk. The schizotypal traits in the NFBC 1966 were assessed in a large (almost 5,000 individuals) follow-up at the age of 31, with the Wisconsin schizotypy scales (Social Anhedonia Scale, Physical Anhedonia Scale, and Perceptual Aberration Scale) and the Hypomanic Personality Scale.

The cohort studies have focused on psychometric properties on these scales and differences in the traits by gender and education [80]. Men reported higher anhedonia, whereas women had higher scores in hypomanic personality and perceptual aberration. Participants with a lower level of education scored higher in all scales [80]. Of the various traits, 
perceptual aberration and hypomanic personality associated most strongly with psychosis diagnoses in the 11-year followup [81], whereas physical anhedonia separated depression from other psychiatric disorders [82]. Many of the earlylife risk factors linked to schizophrenia also associated with schizotypal traits, including, for instance, lower birth weight and gestational age [83].

9.2. Genes Associated with Schizophrenia and Schizotypal Traits. The genetic studies in the NFBC 1966 have focused especially on DISC1 (disrupted-in-schizophrenia 1), finding associations between DISCl and social anhedonia [84]. The authors later reanalyzed the genome-wide association data and found several genes with biological relevance to mental illnesses through loci displaying suggestive evidence for association [85]. Bader et al. [86] found CRMP1 (collapsinresponse mediator protein 1) locus to associate with social and physical anhedonia, suggesting the potential role of CRMP1 expression as a blood-based diagnostic marker. The NFBC 1966 data have also been used in a study that found a positive correlation between neuropeptide precursor VGF single-nucleotide polymorphisms and social anhedonia [87]. It has also been investigated as to whether large copy number variant deletions [88] or Chromosome 22q deletions [89] associate with various neurodevelopmental phenotypes. In these studies, no associations were found with regard to psychotic disorders.

\section{Discussion}

10.1. Main Results. The NFBC 1966 has been especially active for 20 years. The prospective study design and long followup have enabled several clinically and epidemiologically important findings. The early studies in the NFBC 1966 focused on risk factors for schizophrenia. Various risk factors have been found, related to, for example, family history of psychosis, adverse events during pregnancy and delivery, and delays in early developmental milestones. Psychiatric course of illness and outcomes are heterogeneous and unfortunately relatively poor. There are several predictors for outcomes, one of the most important being early age of illness onset. Some of the predictors of outcomes may be modified, such as substance use and duration of untreated psychosis.

There are differences between subjects with schizophrenia and controls in brain volume and densities in several brain areas. Global cognitive functioning and performance in various cognitive domains were worse in schizophrenia than in the controls cross-sectionally, but longitudinally cognition mostly followed the normal course of aging in midlife. High doses of antipsychotics associated with both brain volume loss and decline in cognition, and also more severe illness in terms of symptomatology, the need of hospitalization, and functional outcomes. Additionally, the use of antipsychotics was related to hyperlipidemia. Physical diseases, such as metabolic syndrome and epilepsy, are common in schizophrenia, and mortality is high, especially due to suicides.

10.2. Significance and Novelty of the NFBC 1966 Findings. The NFBC 1966 has provided important knowledge on epidemiology and etiology of schizophrenia. In particular, the possibility of prospectively and reliably analyzing the very early risk factors of schizophrenia is unique. Additionally, the results from the last ten years have brought information that can be utilized in developing clinical practice as well. For example, results on psychiatric and somatic outcomes, mortality, and predictors of outcomes are important with regard to the health promotion and clinical care in schizophrenia. The results also indicate that suicide prevention, early detection and intervention, monitoring somatic health, and active treatment of metabolic abnormalities are highly important. The sample is naturalistic, describing the real-life situation, so the results are generalizable to other settings. The NFBC 1966 studies have analysed also methodological questions, such as diagnostic validity $[45,46]$ and attrition [41-43]. The studies have been basis also for theoretical, holistic longitudinal models in schizophrenia [47].

The especially interesting and novel findings of the NFBC 1966 are those concerning potentially harmful effects of high doses of antipsychotics on changes in brain morphometry and cognitive functioning [37,38]. These results support some earlier studies $[90,91]$, now detecting similar findings in unselected, nonclinical schizophrenia population. The finding of the higher cumulative lifetime dose of antipsychotics and decrease of cognition is new. Earlier studies investigating the association between antipsychotic medication and cognition in schizophrenia have been conducted most commonly in clinical trials with relatively short follow-up, in which two or more antipsychotic drugs are compared with each other. Additionally, high doses of antipsychotics were associated with increased suicidal thoughts among persons without diagnosis of psychosis (i.e., off-label use), even when depression and anxiety symptoms were controlled for [39]. Together with earlier studies [91], these results do not support the view that antipsychotics in general prevent cognitive decline or promote cognitive recovery in schizophrenia and highlight the importance of careful assessment of risks and benefits of dosage and duration of antipsychotic treatment.

10.3. Comparison to Other Birth Cohort Studies. The NFBC 1966 is not the only birth cohort that has studied schizophrenia. Welham et al. [1] have identified 11 birth cohort studies focusing on premorbid developmental trajectories of schizophrenia. Most consistent risk factors identified were behavioral disturbances and psychopathology, intellectual and language deficits, and early motor delays [1]. The NFBC 1966 studies have contributed to conclusions of the review, and especially results regarding early motor developmental delays are comparable to other birth cohort studies and ours. Recently, a register-based Danish National Birth Cohort study has shown that maternal HSV-2 antibodies increase the risk of schizophrenia in offspring [92]. The Prenatal Determinants of Schizophrenia (PDS) study based on the Child Health and Development Study cohort assembled in 1959-1967 in USA has identified various prenatal infection, nutrition, and toxic exposure for schizophrenia; these studies have been reviewed by Bresnahan et al. [93].

Studies on cognition on other birth cohorts have focused mostly on premorbid cognition. MacCabe [94] concluded in 
his review that children and adolescents with poor cognitive abilities in childhood are at increased risk of schizophrenia. Regarding adulthood cognition, patients exposed to maternal genital/reproductive infection performed more poorly on verbal memory, fine-motor coordination, and working memory in a US birth cohort (Child Health and Development Study) [95]. Also low birth weight has been linked with cognitive impairment in schizophrenia [96]. In the Dunedin cohort, including cognitive tests both before and after onset of schizophrenia disease specific decline in IQ and various mental functions in schizophrenia was found [97]. Later age of learning to stand in infancy predicted deterioration of executive functions with memory in schizophrenia between 34 and 43 years of age in the NFBC 1966 [60]. These abovementioned studies support the idea of neurodevelopmental but also neurodegenerative processes in schizophrenia.

To our knowledge only one other birth cohort study has focused on brain MRI, showing structural alterations of the cerebral cortex, particularly in the frontal and temporal lobes, and ventricular enlargement in schizophrenia [98], as in our sample.

Somatic comorbidities have been studied in the Helsinki Birth Cohort Study, where individuals with schizophrenia had a higher risk of hospitalization and mortality for coronary heart disease; however, patients with schizophrenia used less lipid-lowering and antihypertensive drug treatment [99]. These and the results of our study highlight the importance of both detecting and treating the somatic illness in schizophrenia early and efficiently. As in our study, violence and criminality have been studied, for example, in the Dunedin Birth Cohort, where the researchers found that those with schizophrenia were 2.5 times more likely to be violent than control subjects [100].

The register-based Danish national birth cohort has been utilized when studying family history and variation in single-nucleotide polymorphisms to risk of schizophrenia. Agerbo et al. [101] found that offspring schizophrenia risk was elevated in those whose mother, father, or siblings had been diagnosed with schizophrenia or related psychosis, bipolar affective disorder, or any other psychiatric disorder. Regarding schizotypal symptoms, in the Australian MaterUniversity of Queensland Study of Pregnancy, high childhood psychopathology predicted high levels of delusionallike experiences at the age of 21 [102].

There is also younger birth cohort based on the same geographical area than the NFBC 1966; the studies relating to schizophrenia in the Northern Finland Birth Cohort 1986 have so far studied mainly those with clinical or familial risk for psychosis or schizophrenia [103].

In all, many of the risk factor findings from the NFBC 1966 have been replicated in other birth cohorts. To our knowledge, other birth cohort studies have not analyzed clinical and occupational course of illness and their determinants after onset of schizophrenia, though these kind of clinically relevant studies would be especially important in epidemiologically sound samples like birth cohorts. There is a lack of birth cohort studies with straight clinical implications, including postmorbid data, and this should be corrected in the future as birth cohorts get older.
10.4. Strengths and Limitations. The strengths of the birth cohort samples in general and also of the NFBC 1966 include the prospective design and large number of unselected matched controls. This design provides unique possibilities of analyzing causal relationships, for example, between risk factors during pregnancy and delivery and later risk of illness. The major benefit in the NFBC 1966 is also the ability to utilize large nationwide health registers [104]. Linking the cohort data to register data enables researchers to study relatively easily and with low attrition various outcomes, such as hospital treatments, employment, use of social benefits, and mortality. The NFBC 1966 studies utilizing cognitive and brain imaging data differ from most of the other studies on these topics, as in those studies cases are often from clinical samples, collected from one treatment setting, and controls are not included or are selected volunteers.

The NFBC 1966 and other birth cohort studies have various limitations. Participants are not randomly assigned to exposure; thus, any observed associations may be confounded by unmeasured factors. For example, very sick individuals get more antipsychotics than persons with minimal symptomatology. Also, naturally, birth cohort studies include only case and outcome data until the point of data collection used in each study. In the birth cohort studies, the number of cases is often relatively small and power to detect even moderate signal may be low. Additionally, originally birth cohort was not planned for schizophrenia studies specifically: this means that all relevant data regarding schizophrenia research has not been collected (e.g., childhood behaviour and symptoms or treatment aspects, especially regarding psychosocial treatments).

\section{Conclusions}

Schizophrenia research has been conducted for over 20 years in the NFBC 1966. Several interesting and unique findings regarding risk factors, somatic and psychiatric outcomes, brain morphology and cognition, antipsychotics use, and genetics have been reported. In the future, with the cohort members aging, somatic health, consequences of the use of antipsychotics, and the long-term psychiatric and functional outcomes will be important to explore.

\section{Disclosure}

The funders had no role in the design or conduct of the study.

\section{Conflict of Interests}

The authors declare that there is no conflict of interests regarding the publication of this paper.

\section{Acknowledgments}

This study has been funded by the Academy of Finland (no. 132071, no. 268336, and no. 278286), Brain and Behavior Research Foundation, Jalmari and Rauha Ahokas Foundation, Sigrid Jusélius Foundation, and Northern Finland 
Health Care Support Foundation. The authors would like to acknowledge all the participants in this study and researchers collecting the data.

\section{References}

[1] J. Welham, M. Isohanni, P. Jones, and J. McGrath, "The antecedents of Schizophrenia: a review of birth cohort studies," Schizophrenia Bulletin, vol. 35, no. 3, pp. 603-623, 2009.

[2] P. Rantakallio, "Groups at risk in low birth weight infants and perinatal mortality," Acta Paediatrica Scandinavica, vol. 193, supplement 193, pp. 1-71, 1969.

[3] P. Rantakallio, P. Jones, J. Moring, and L. von Wendt, "Association between central nervous system infections during childhood and adult onset schizophrenia and other psychoses: a 28year follow-up," International Journal of Epidemiology, vol. 26, no. 4, pp. 837-843, 1997.

[4] S. Räsänen, J. Veijola, H. Hakko, M. Joukamaa, and M. Isohanni, "Gender differences in incidence and age at onset of DSM-IIIR schizophrenia. Preliminary results of the Northern Finland 1966 birth cohort study," Schizophrenia Research, vol. 37, no. 2, pp. 197-198, 1999.

[5] E. Keskinen, J. Miettunen, H. Koivumaa-Honkanen, P. Mäki, M. Isohanni, and E. Jääskeläinen, "Interaction between parental psychosis and risk factors during pregnancy and birth for schizophrenia-the Northern Finland 1966 Birth Cohort study," Schizophrenia Research, vol. 145, no. 1-3, pp. 56-62, 2013.

[6] P. Mäki, J. Veijola, P. Rantakallio, J. Jokelainen, P. B. Jones, and M. Isohanni, "Schizophrenia in the offspring of antenatally depressed mothers: a 31-year follow-up of the Northern Finland 1966 Birth Cohort," Schizophrenia Research, vol. 66, no. 1, pp. 79-81, 2004.

[7] A. Myhrman, P. Rantakallio, M. Isohanni, P. Jones, and U. Rartanen, "Unwantedness of a pregnancy and schizophrenia in the child," British Journal of Psychiatry, vol. 169, no. 5, pp. 637640, 1996.

[8] T. Mäkikyrö, M. Isohanni, J. Moring et al., "Is a child's risk of early onset schizophrenia increased in the highest social class?" Schizophrenia Research, vol. 23, no. 3, pp. 245-252, 1997.

[9] P. B. Jones, P. Rantakallio, A.-L. Hartikainen, M. Isohanni, and P. Sipila, "Schizophrenia as a long-term outcome of pregnancy, delivery, and perinatal complications: a 28-year follow-up of the 1966 North Finland general population birth cohort," The American Journal of Psychiatry, vol. 155, no. 3, pp. 355-364, 1998.

[10] K. Moilanen, J. Jokelainen, P. B. Jones, A.-L. Hartikainen, M.R. Järvelin, and M. Isohanni, "Deviant intrauterine growth and risk of schizophrenia: a 34-year follow-up of the Northern Finland 1966 Birth Cohort," Schizophrenia Research, vol. 124, no. 1-3, pp. 223-230, 2010.

[11] L. Kemppainen, J. Veijola, J. Jokelainen et al., "Birth order and risk for schizophrenia: a 31-year follow-up of the Northern Finland 1966 Birth Cohort," Acta Psychiatrica Scandinavica, vol. 104, no. 2, pp. 148-152, 2001.

[12] L. Kemppainen, T. Mäkikyrö, J. Jokelainen, P. Nieminen, M.-R. Järvelin, and M. Isohanni, "Is grand multiparity associated with offsprings' hospital-treated mental disorders? A 28-year followup of the North Finland 1966 birth cohort," Social Psychiatry and Psychiatric Epidemiology, vol. 35, no. 3, pp. 104-108, 2000.

[13] J. McGrath, K. Saari, H. Hakko et al., "Vitamin D supplementation during the first year of life and risk of schizophrenia: a Finnish birth cohort study," Schizophrenia Research, vol. 67, no. 2-3, pp. 237-245, 2004.
[14] M. Isohanni, P. B. Jones, K. Moilanen et al., "Early developmental milestones in adult schizophrenia and other psychoses. A 31-year follow-up of the Northern Finland 1966 Birth Cohort," Schizophrenia Research, vol. 52, no. 1-2, pp. 1-19, 2001.

[15] T. Mäkikyrö, A. Sauvola, J. Moring et al., "Hospital-treated psychiatric disorders in adults with a single-parent and twoparent family background: a 28-year follow-up of the 1966 Northern Finland Birth Cohort," Family Process, vol. 37, no. 3, pp. 335-344, 1998.

[16] H. Koponen, P. Rantakallio, J. Veijola, P. Jones, J. Jokelainen, and M. Isohanni, "Childhood central nervous system infections and risk for schizophrenia," European Archives of Psychiatry and Clinical Neuroscience, vol. 254, no. 1, pp. 9-13, 2004.

[17] I. Isohanni, M.-R. Järvelin, P. Jones, J. Jokelainen, and M. Isohanni, "Can excellent school performance be a precursor of schizophrenia? A 28-year follow-up in the Northern Finland 1966 birth cohort," Acta Psychiatrica Scandinavica, vol. 100, no. 1, pp. 17-26, 1999.

[18] I. Isohanni, M.-R. Järvelin, P. Nieminen et al., "School performance as a predictor of psychiatric hospitalization in adult life. A 28-year follow-up in the Northern Finland 1966 Birth Cohort," Psychological Medicine, vol. 28, no. 4, pp. 967-974, 1998.

[19] S. Luoma, H. Hakko, M. Marttunen, A. Taanila, and S. Lindeman, "Severe injuries in adolescence predict psychosis: a nested case control study of the Northern Finland 1966 Birth Cohort," Schizophrenia Research, vol. 118, no. 1-3, pp. 48-53, 2010.

[20] P. Rasanen, H. Hakko, M.-R. Jarvelin, M. Isohanni, and J. Tiihonen, "Schizophrenia and seasonality of admissions: the Northern Finland 1966 birth cohort study," Schizophrenia Research, vol. 35, no. 2, pp. 183-185, 1999.

[21] B. Miller, E. Messias, J. Miettunen et al., "Meta-analysis of paternal age and schizophrenia risk in male versus female offspring," Schizophrenia Bulletin, vol. 37, no. 5, pp. 1039-1047, 2011.

[22] P. Mäki, T. Riekki, J. Miettunen et al., "Schizophrenia in the offspring of antenatally depressed mothers in the Northern Finland 1966 birth cohort: Relationship to family history of psychosis," The American Journal of Psychiatry, vol. 167, no. 1, pp. 70-77, 2010.

[23] M. Isohanni, G. K. Murray, J. Jokelainen, T. Croudace, and P. B. Jones, "The persistence of developmental markers in childhood and adolescence and risk for schizophrenic psychoses in adult life. A 34-year follow-up of the Northern Finland 1966 birth cohort," Schizophrenia Research, vol. 71, no. 2-3, pp. 213-225, 2004.

[24] B. Miller, J. Suvisaari, J. Miettunen et al., "Advanced paternal age and parental history of schizophrenia," Schizophrenia Research, vol. 133, no. 1-3, pp. 125-132, 2011.

[25] E. Lauronen, J. Miettunen, J. Veijola, M. Karhu, P. B. Jones, and M. Isohanni, "Outcome and its predictors in schizophrenia within the Northern Finland 1966 Birth Cohort," European Psychiatry, vol. 22, no. 2, pp. 129-136, 2007.

[26] J. Miettunen, E. Lauronen, J. Veijola, H. Koponen, O. Saarento, and M. Isohanni, "Patterns of psychiatric hospitalizations in schizophrenic psychoses within the Northern Finland 1966 birth cohort," Nordic Journal of Psychiatry, vol. 60, no. 4, pp. 286-293, 2006.

[27] P. Juola, J. Miettunen, J. Veijola, M. Isohanni, and E. Jääskeläinen, "Predictors of short-and long-term clinical outcome in schizophrenic psychosis-the Northern Finland 
1966 Birth Cohort study," European Psychiatry, vol. 28, no. 5, pp. 263-268, 2013.

[28] E. Jääskeläinen, J. Miettunen, J. Veijola et al., "Associations between early development and outcome in schizophrenia-a 35-year follow-up of the Northern Finland 1966 Birth Cohort," Schizophrenia Research, vol. 99, no. 1-3, pp. 29-37, 2008.

[29] E. Jääskeläinen, P. Juola, J. Kurtti et al., "Associations between brain morphology and outcome in schizophrenia in a general population sample," European Psychiatry, vol. 29, no. 7, pp. 456462, 2014.

[30] M. Penttilä, J. Miettunen, H. Koponen et al., "Association between the duration of untreated psychosis and short- and long-term outcome in schizophrenia within the Northern Finland 1966 Birth Cohort," Schizophrenia Research, vol. 143, no. 1, pp. 3-10, 2013.

[31] J. Mäkinen, J. Miettunen, E. Jääskeläinen, J. Veijola, M. Isohanni, and H. Koponen, "Negative symptoms and their predictors in schizophrenia within the Northern Finland 1966 Birth Cohort," Psychiatry Research, vol. 178, no. 1, pp. 121-125, 2010.

[32] L. Poustka, G. K. Murray, E. Jääskeläinen et al., "The influence of temperament on symptoms and functional outcome in people with psychosis in the Northern Finland 1966 Birth Cohort," European Psychiatry, vol. 25, no. 1, pp. 26-32, 2010.

[33] T. Mäkikyrö, E. Leinonen, H. Koponen et al., "Early developmental differences between DSM-III-R schizophrenics treated with clozapine and typical neuroleptics," Journal of Psychiatric Research, vol. 32, no. 2, pp. 105-110, 1998.

[34] J. Miettunen, E. Lauronen, J. Veijola et al., "Socio-demographic and clinical predictors of occupational status in schizophrenic psychoses-follow-up within the Northern Finland 1966 Birth Cohort," Psychiatry Research, vol. 150, no. 3, pp. 217-225, 2007.

[35] S. Luoma, H. Hakko, T. Ollinen, M.-R. Järvelin, and S. Lindeman, "Association between age at onset and clinical features of schizophrenia: the Northern Finland 1966 birth cohort study," European Psychiatry, vol. 23, no. 5, pp. 331-335, 2008.

[36] J. Moilanen, M. Haapea, J. Miettunen et al., "Characteristics of subjects with schizophrenia spectrum disorder with and without antipsychotic medication-a 10-year follow-up of the Northern Finland 1966 Birth Cohort study," European Psychiatry, vol. 28, no. 1, pp. 53-58, 2013.

[37] J. Veijola, J. Y. Guo, J. S. Moilanen et al., "Longitudinal changes in total brain volume in schizophrenia: relation to symptom severity, cognition and antipsychotic medication," PLOS ONE, vol. 9, no. 7, Article ID e101689, 2014.

[38] A. P. Husa, I. Rannikko, J. Moilanen et al., "Lifetime use of antipsychotic medication and its relation to change of verbal learning and memory in midlife schizophrenia-an observational 9-year follow-up study,' Schizophrenia Research, vol. 158, no. 1-3, pp. 134-141, 2014.

[39] I. Rissanen, E. Jääskeläinen, M. Isohanni et al., "Use of antipsychotic medication and suicidality-the Northern Finland Birth Cohort 1966," Human Psychopharmacology, vol. 27, no. 5, pp. 476-485, 2012.

[40] K. Saari, H. Koponen, J. Laitinen et al., "Hyperlipidemia in persons using antipsychotic medication: a general populationbased birth cohort study," The Journal of Clinical Psychiatry, vol. 65, no. 4, pp. 547-550, 2004.

[41] M. Haapea, J. Miettunen, E. Läärä et al., "Non-participation in a field survey with respect to psychiatric disorders," Scandinavian Journal of Public Health, vol. 36, no. 7, pp. 728-736, 2008.

[42] M. Haapea, J. Miettunen, J. Veijola, E. Lauronen, P. Tanskanen, and M. Isohanni, "Non-participation may bias the results of a psychiatric survey. An analysis from the survey including magnetic resonance imaging within the Northern Finland 1966 Birth Cohort," Social Psychiatry and Psychiatric Epidemiology, vol. 42, no. 5, pp. 403-409, 2007.

[43] M. Haapea, J. Veijola, P. Tanskanen, E. Jääskeläinen, M. Isohanni, and J. Miettunen, "Use of inverse probability weighting to adjust for non-participation in estimating brain volumes in schizophrenia patients," Psychiatry Research, vol. 194, no. 3, pp. 326-332, 2011.

[44] M. Haapea, M. Isohanni, E. Jääskeläinen, J. Veijola, and J. Miettunen, "Using home recruitment to increase representativeness of schizophrenia research," European Psychiatry, vol. 28, supplement 1, meeting abstract 1725, 2013.

[45] M. Isohanni, T. Mäkikyrö, J. Moring et al., "A comparison of clinical and research DSM-III-R diagnoses of schizophrenia in a Finnish national birth cohort. Clinical and research diagnoses of schizophrenia," Social Psychiatry and Psychiatric Epidemiology, vol. 32, no. 5, pp. 303-308, 1997.

[46] K. Moilanen, J. Veijola, K. Läksy et al., "Reasons for the diagnostic discordance between clinicians and researchers in schizophrenia in Northern Finland 1966 Birth Cohort," Social Psychiatry and Psychiatric Epidemiology, vol. 38, no. 6, pp. 305310, 2003.

[47] M. Isohanni, J. Miettunen, P. Mäki et al., "Risk factors for schizophrenia. Follow-up data from the Northern Finland 1966 Birth Cohort Study," World Psychiatry, vol. 5, no. 3, pp. 168-171, 2006.

[48] S. L. Matheson, A. M. Shepherd, K. R. Laurens, and V. J. Carr, "A systematic meta-review grading the evidence for nongenetic risk factors and putative antecedents of schizophrenia," Schizophrenia Research, vol. 133, no. 1-3, pp. 133-142, 2011.

[49] E. Lauronen, J. Koskinen, J. Veijola et al., "Recovery from schizophrenic psychoses within the northern Finland 1966 birth cohort," Journal of Clinical Psychiatry, vol. 66, no. 3, pp. 375-383, 2005.

[50] I. Isohanni, P. B. Jones, M.-R. Järvelin et al., "Educational consequences of mental disorders treated in hospital. A 31year follow-up of the Northern Finland 1966 Birth Cohort," Psychological Medicine, vol. 31, no. 2, pp. 339-349, 2001.

[51] E. Jääskeläinen, P. Juola, N. Hirvonen et al., "A systematic review and meta-analysis of recovery in schizophrenia," Schizophrenia Bulletin, vol. 39, no. 6, pp. 1296-1306, 2013.

[52] M. Penttilä, E. Jääskeläinen, N. Hirvonen, M. Isohanni, and J. Miettunen, "Duration of untreated psychosis as predictor of long-term outcome in schizophrenia: systematic review and meta-analysis," The British Journal of Psychiatry, vol. 205, no. 2, pp. 88-94, 2014.

[53] P. Fusar-Poli, S. Borgwardt, A. Bechdolf et al., "The psychosis high-risk state: a comprehensive state-of-the-art review," Archives of General Psychiatry, vol. 70, no. 1, pp. 107-120, 2013.

[54] P. Tanskanen, M. Haapea, J. Veijola et al., "Volumes of brain, grey and white matter and cerebrospinal fluid in schizophrenia in the Northern Finland 1966 Birth Cohort: an epidemiological approach to analysis," Psychiatry Research, vol. 174, no. 2, pp. 116-120, 2009.

[55] P. Tanskanen, K. Ridler, M. Haapea et al., "Morphometric brain abnormalities in schizophrenia in a population-based sample: relationship to duration of illness," Schizophrenia Bulletin, vol. 36, no. 4, pp. 766-777, 2010.

[56] P. Tanskanen, J. M. Veijola, U. K. Piippo et al., "Hippocampus and amygdala volumes in schizophrenia and other psychoses 
in the Northern Finland 1966 birth cohort," Schizophrenia Research, vol. 75, no. 2-3, pp. 283-294, 2005.

[57] M. Penttilä, E. Jääskeläinen, M. Haapea et al., "Association between duration of untreated psychosis and brain morphology in schizophrenia within the Northern Finland 1966 Birth Cohort," Schizophrenia Research, vol. 123, no. 2-3, pp. 145-152, 2010.

[58] K. Ridler, J. M. Veijola, P. Tanskanen et al., "Fronto-cerebellar systems are associated with infant motor and adult executive functions in healthy adults but not in schizophrenia," Proceedings of the National Academy of Sciences of the United States of America, vol. 103, no. 42, pp. 15651-15656, 2006.

[59] G. K. Murray, P. B. Jones, K. Moilanen et al., "Infant motor development and adult cognitive functions in schizophrenia," Schizophrenia Research, vol. 81, no. 1, pp. 65-74, 2006.

[60] H. Kobayashi, M. Isohanni, E. Jääskeläinen et al., "Linking the developmental and degenerative theories of schizophrenia: association between infant development and adult cognitive decline," Schizophrenia Bulletin, vol. 40, no. 6, pp. 1319-1327, 2014.

[61] I. Rannikko, M. Haapea, J. Miettunen et al., "Longitudinal change in verbal learning and memory in schizophrenia and controls: a nine-year study in the Northern Finland Birth Cohort 1966," European Psychiatry, vol. 28, supplement 1, meeting abstract 1913, 2013.

[62] E. Bora and R. M. Murray, "Meta-analysis of cognitive deficits in ultra-high risk to psychosis and first-episode psychosis: do the cognitive deficits progress over, or after, the onset of psychosis?" Schizophrenia Bulletin, vol. 40, no. 4, pp. 744-755, 2014.

[63] K. Riala, H. Hakko, M. Isohanni, A. Pouta, and P. Räsänen, "Is initiation of smoking associated with the prodromal phase of schizophrenia?" Journal of Psychiatry and Neuroscience, vol. 30, no. 1, pp. 26-32, 2005.

[64] K. Riala, H. Hakko, M. Isohanni, J. Jokelainen, M. Weiser, and P. Räsänen, "Poor premorbid school performance is associated with later cigarette smoking among schizophrenia patients," Psychiatry Research, vol. 137, no. 1-2, pp. 137-141, 2005.

[65] H. Hakko, M. T. Komulainen, H. Koponen et al., "Are females at special risk of obesity if they become psychotic? The longitudinal Northern Finland 1966 Birth Cohort Study," Schizophrenia Research, vol. 84, no. 1, pp. 15-19, 2006.

[66] K. M. Saari, S. M. Lindeman, K. M. Viilo et al., "A 4-fold risk of metabolic syndrome in patients with schizophrenia: the Northern Finland 1966 birth cohort study," Journal of Clinical Psychiatry, vol. 66, no. 5, pp. 559-563, 2005.

[67] H. J. Koponen, H. H. Hakko, K. M. Saari et al., "The prevalence and predictive value of individual criteria for metabolic syndrome in schizophrenia: a Northern Finland 1966 Birth Cohort Study," World Journal of Biological Psychiatry, vol. 11, no. 2, part 2, pp. 262-267, 2010.

[68] M. J. Timonen, K. M. Saari, J. J. Jokelainen, V. B. Meyer-Rochow, P. K. Räsänen, and H. J. Koponen, "Insulin resistance and schizophrenia: results from the Northern Finland 1966 Birth Cohort," Schizophrenia Research, vol. 113, no. 1, pp. 107-108, 2009.

[69] K. Saari, J. Jokelainen, J. Veijola et al., "Serum lipids in schizophrenia and other functional psychoses: a general population northern Finland 1966 birth cohort survey," Acta Psychiatrica Scandinavica, vol. 110, no. 4, pp. 279-285, 2004.

[70] K. Saari, S. Lindeman, H. Koponen, J. Jokelainen, and M. Isohanni, "Higher serum triglyceride levels in early-onset schizophrenia," The American Journal of Psychiatry, vol. 161, no. 1, p. 176, 2004.

[71] T. Mäkikyrö, J. T. Karvonen, H. Hakko et al., "Comorbidity of hospital-treated psychiatric and physical disorders with special reference to schizophrenia: a 28 year follow-up of the 1966 northern Finland general population birth cohort," Public Health, vol. 112, no. 4, pp. 221-228, 1998.

[72] H. Lauerma, V. Lehtinen, M. Joukamaa, M.-R. Järvelin, H. Helenius, and M. Isohanni, "Schizophrenia among patients treated for rheumatoid arthritis and appendicitis," Schizophrenia Research, vol. 29, no. 3, pp. 255-261, 1998.

[73] P. Räsänen, J. Tiihonen, M. Isohanni, J. Moring, and M. Koiranen, "Juvenile mortality, mental disturbances and criminality: a prospective study of the Northern Finland 1966 birth cohort," Acta Psychiatrica Scandinavica, vol. 97, no. 1, pp. 5-9, 1998.

[74] A. Alaräisänen, J. Miettunen, P. Räsänen, W. Fenton, H.-T. J. Koivumaa-Honkanen, and M. Isohanni, "Suicide rate in schizophrenia in the Northern Finland 1966 Birth Cohort," Social Psychiatry and Psychiatric Epidemiology, vol. 44, no. 12, pp. 1107-1110, 2009.

[75] A. Alaräisänen, J. Miettunen, E. Lauronen, P. Räsänen, and M. Isohanni, "Good school performance is a risk factor of suicide in psychoses: a 35-year follow up of the Northern Finland 1966 Birth Cohort," Acta Psychiatrica Scandinavica, vol. 114, no. 5, pp. 357-362, 2006.

[76] K. A. Nolan, J. Volavka, P. Czobor et al., "Suicidal behavior in patients with schizophrenia is related to COMT polymorphism," Psychiatric Genetics, vol. 10, no. 3, pp. 117-124, 2000.

[77] J. Tiihonen, M. Isohanni, P. Räsänen, M. Koiranen, and J. Moring, "Specific major mental disorders and criminality: a 26-year prospective study of the 1966 Northern Finland birth cohort," The American Journal of Psychiatry, vol. 154, no. 6, pp. 840-845, 1997.

[78] P. Rasanen, J. Tiihonen, M. Isohanni, P. Rantakallio, J. Lehtonen, and J. Moring, "Schizophrenia, alcohol abuse, and violent behavior: a 26-year followup study of an unselected birth cohort," Schizophrenia Bulletin, vol. 24, no. 3, pp. 437-441, 1998.

[79] Schizophrenia Working Group of the Psychiatric Genomics Consortium, "Biological insights from 108 schizophreniaassociated genetic loci," Nature, vol. 511, no. 7510, pp. 421-427, 2014.

[80] J. Miettunen, J. Veijola, N. Freimer et al., "Data on schizotypy and affective scales are gender and education dependentstudy in the Northern Finland 1966 Birth Cohort," Psychiatry Research, vol. 178, no. 2, pp. 408-413, 2010.

[81] J. Miettunen, J. Veijola, M. Isohanni et al., "Identifying schizophrenia and other psychoses with psychological scales in the general population," Journal of Nervous and Mental Disease, vol. 199, no. 4, pp. 230-238, 2011.

[82] J. Miettunen, M. Isohanni, T. Paunio et al., "Predicting depression with psychopathology and temperament traits-the Northern Finland 1966 birth cohort," Depression Research and Treatment, vol. 2012, Article ID 160905, 9 pages, 2012.

[83] J. Lahti, K. Räikkönen, U. Sovio et al., "Early-life origins of schizotypal traits in adulthood," British Journal of Psychiatry, vol. 195, no. 2, pp. 132-137, 2009.

[84] L. Tomppo, W. Hennah, J. Miettunen et al., "Association of variants in DISC1 with psychosis-related traits in a large population cohort," Archives of General Psychiatry, vol. 66, no. 2, pp. 134-141, 2009.

[85] L. Tomppo, J. Ekelund, D. Lichtermann, J. Veijola, M.-R. Järvelin, and W. Hennah, "DISC1 conditioned GWAS for 
psychosis proneness in a large Finnish birth cohort," PLoS ONE, vol. 7, no. 2, Article ID e30643, 2012.

[86] V. Bader, L. Tomppo, S. V. Trossbach et al., "Proteomic, genomic and translational approaches identify CRMP1 for a role in schizophrenia and its underlying traits," Human Molecular Genetics, vol. 21, no. 20, Article ID dds273, pp. 4406-4418, 2012.

[87] A. Ramos, C. Rodríguez-Seoane, I. Rosa et al., "Neuropeptide precursor VGF is genetically associated with social anhedonia and underrepresented in the brain of major mental illness: its downregulation by DISC1," Human Molecular Genetics, vol. 23, no. 22, pp. 5859-5865, 2014.

[88] O. P. H. Pietiläinen, K. Rehnström, E. Jakkula et al., "Phenotype mining in CNV carriers from a population cohort," Human Molecular Genetics, vol. 20, no. 13, pp. 2686-2695, 2011.

[89] G. Stoll, O. P. H. Pietiläinen, B. Linder et al., "Deletion of TOP $3 \beta$, a component of FMRP-containing mRNPs, contributes to neurodevelopmental disorders," Nature Neuroscience, vol. 16, no. 9, pp. 1228-1237, 2013.

[90] B.-C. Ho, N. C. Andreasen, S. Ziebell, R. Pierson, and V. Magnotta, "Long-term antipsychotic treatment and brain volumes: a longitudinal study of first-episode schizophrenia," Archives of General Psychiatry, vol. 68, no. 2, pp. 128-137, 2011.

[91] P. Fusar-Poli, R. Smieskova, M. J. Kempton, B. C. Ho, N. C. Andreasen, and S. Borgwardt, "Progressive brain changes in schizophrenia related to antipsychotic treatment? A metaanalysis of longitudinal MRI studies," Neuroscience \& Biobehavioral Reviews, vol. 37, no. 8, pp. 1680-1691, 2013.

[92] P. B. Mortensen, C. B. Pedersen, D. M. Hougaard et al., "A Danish National Birth Cohort study of maternal HSV-2 antibodies as a risk factor for schizophrenia in their offspring," Schizophrenia Research, vol. 122, no. 1-3, pp. 257-263, 2010.

[93] M. Bresnahan, C. A. Schaefer, A. S. Brown, and E. S. Susser, "Prenatal determinants of schizophrenia: what we have learned thus far?" Epidemiologia e Psichiatria Sociale, vol. 14, no. 4, pp. 194-197, 2005.

[94] J. H. MacCabe, "Population-based cohort studies on premorbid cognitive function in schizophrenia," Epidemiologic Reviews, vol. 30, no. 1, pp. 77-83, 2008.

[95] A. S. Brown, S. Vinogradov, W. S. Kremen et al., "Association of maternal genital and reproductive infections with verbal memory and motor deficits in adult schizophrenia," Psychiatry Research, vol. 188, no. 2, pp. 179-186, 2011.

[96] D. Freedman, Y. Bao, W. S. Kremen, S. Vinogradov, I. W. McKeague, and A. S. Brown, "Birth weight and neurocognition in schizophrenia spectrum disorders," Schizophrenia Bulletin, vol. 39, no. 3, pp. 592-600, 2013.

[97] M. H. Meier, A. Caspi, A. Reichenberg et al., "Neuropsychological decline in schizophrenia from the premorbid to the postonset period: evidence from a population-representative longitudinal study," The American Journal of Psychiatry, vol. 171, no. 1, pp. 91-101, 2014.

[98] T. D. Cannon, T. G. M. van Erp, M. Huttunen et al., "Regional gray matter, white matter, and cerebrospinal fluid distributions in schizophrenic patients, their siblings, and controls," Archives of General Psychiatry, vol. 55, no. 12, pp. 1084-1091, 1998.

[99] M. Lahti, J. Tiihonen, H. Wildgust et al., "Cardiovascular morbidity, mortality and pharmacotherapy in patients with schizophrenia," Psychological Medicine, vol. 42, no. 11, pp. 22752285, 2012.

[100] L. Arseneault, T. E. Moffitt, A. Caspi, P. J. Taylor, and P. A. Silva, "Mental disorders and violence in a total birth cohort: results from the Dunedin study," Archives of General Psychiatry, vol. 57, no. 10, pp. 979-986, 2000.

[101] E. Agerbo, P. B. Mortensen, C. Wiuf et al., "Modelling the contribution of family history and variation in single nucleotide polymorphisms to risk of schizophrenia: a Danish national birth cohort-based study," Schizophrenia Research, vol. 134, no. 2-3, pp. 246-252, 2012.

[102] J. Scott, G. Martin, J. Welham et al., "Psychopathology during childhood and adolescence predicts delusional-like experiences in adults: a 21-year birth cohort study," American Journal of Psychiatry, vol. 166, no. 5, pp. 567-574, 2009.

[103] J. Veijola, P. Mäki, E. Jääskeläinen et al., "Young people at risk for psychosis: case finding and sample characteristics of the Oulu Brain and Mind Study," Early Intervention in Psychiatry, vol. 7, no. 2, pp. 146-154, 2013.

[104] J. Miettunen, J. Suvisaari, J. Haukka, and M. Isohanni, "Use of register data for psychiatric epidemiology in the Nordic countries," in Textbook in Psychiatric Epidemiology, M. Tsuang, M. Tohen, and P. Jones, Eds., pp. 117-131, Wiley-Blackwell, Singapore, 3rd edition, 2011. 


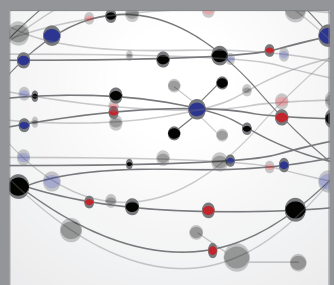

The Scientific World Journal
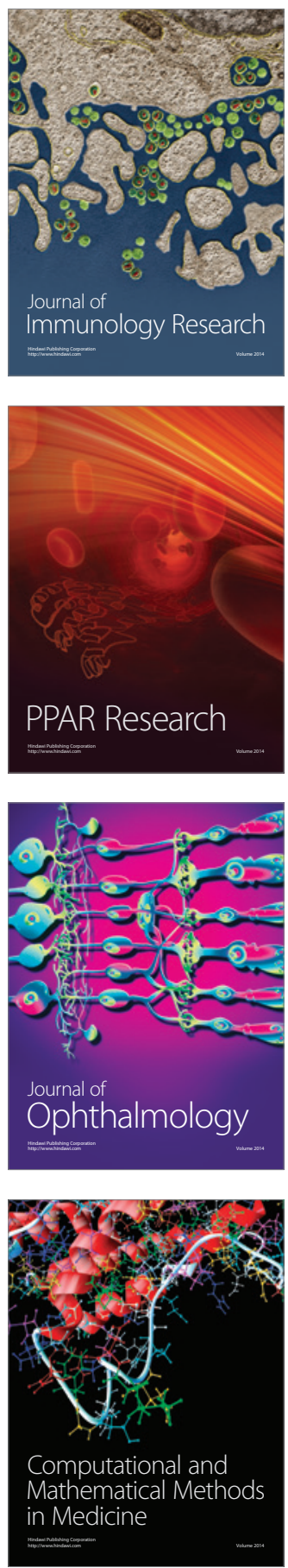

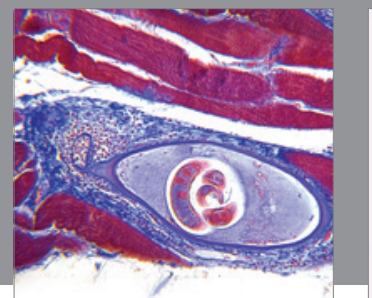

Gastroenterology

Research and Practice
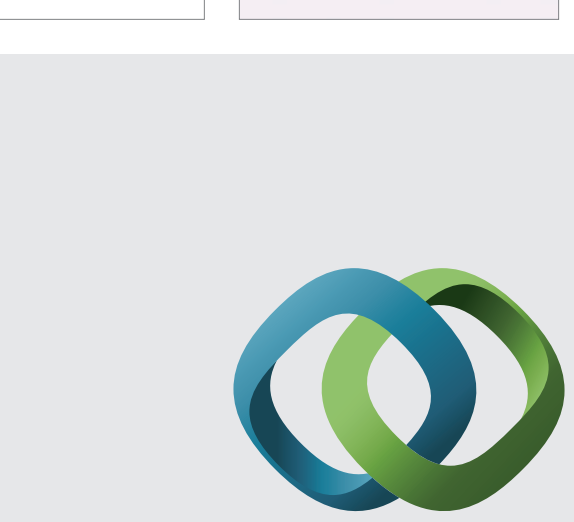

\section{Hindawi}

Submit your manuscripts at

http://www.hindawi.com
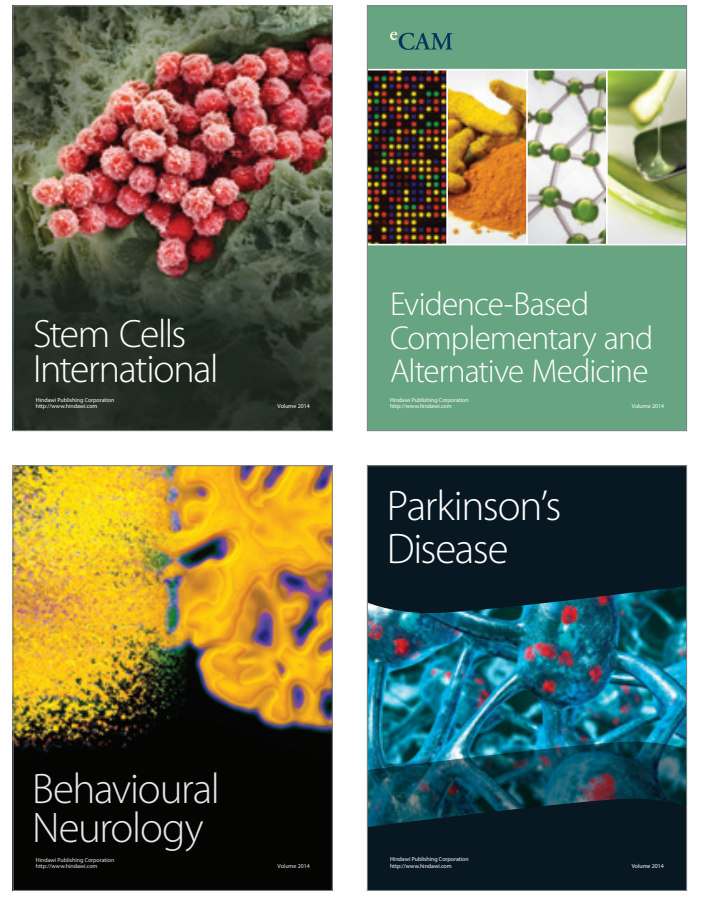
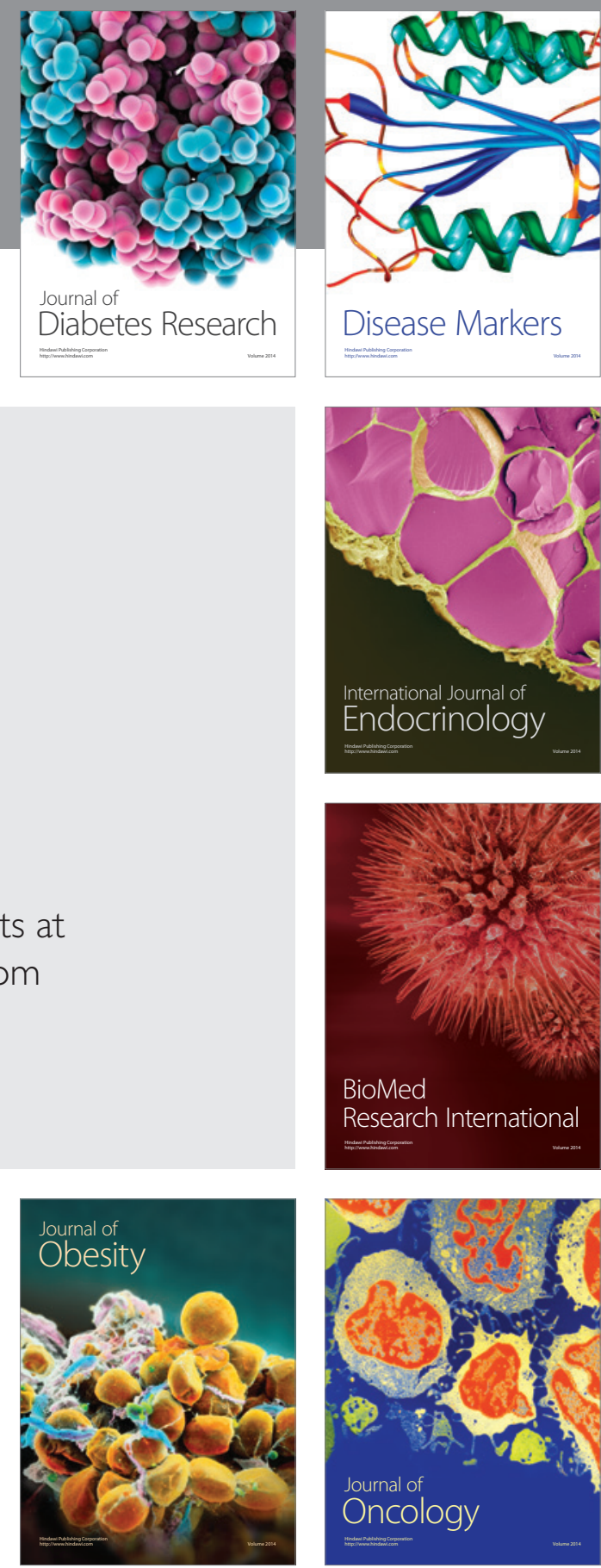

Disease Markers
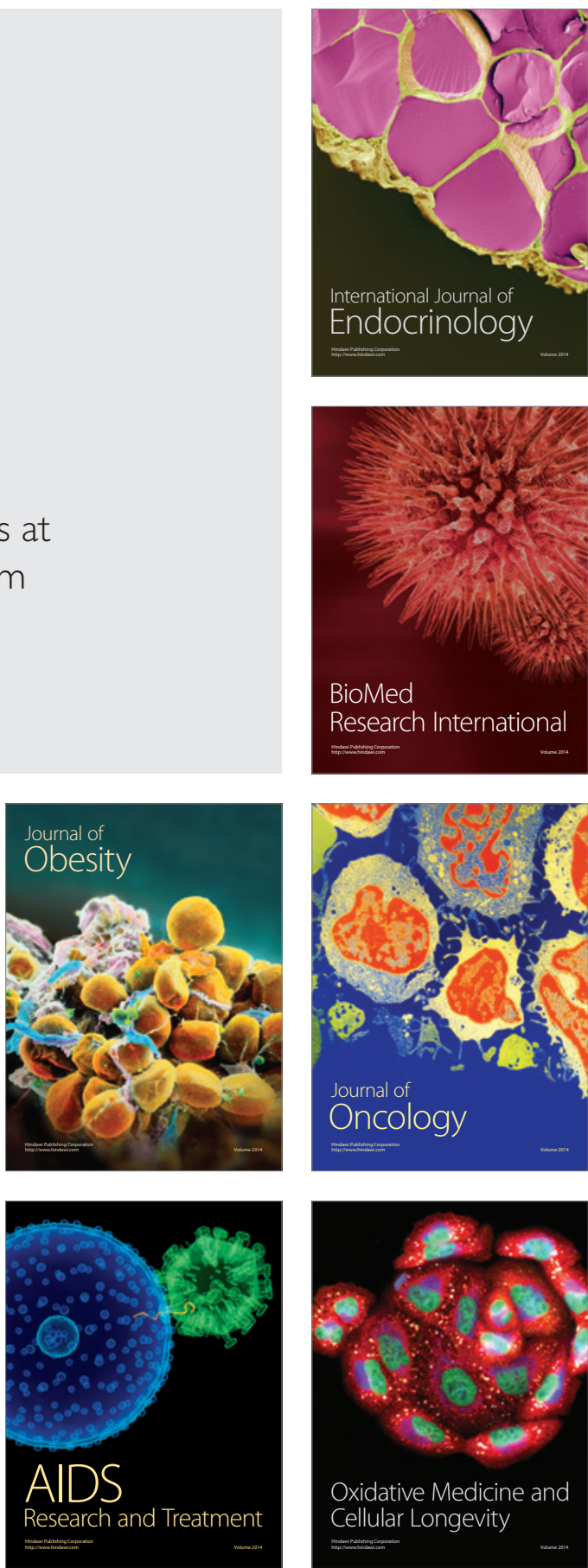